\title{
MONTREAL Y LA RESIDENCIA EN SU ESPACIO CENTRAL: EL CASO DE SAINTE-MARIE DESDE
} LA PERSPECTIVA DE SU ATRACCIÓN

\section{Carlos Alberto Tello}

\section{RESUMEN}

Esta investigación empírica indica lo imperativo de equilibrar el incontrolable crecimiento periférico de ciudades con un arraigo residencial central. Cuestiona la posición oficial del censo Canadiense que informa lo "considerable" del movimiento de re-densificación en el centro de Montreal. Una metodología apoyada en sondeos de opinión presenta como objetivo al diseño de un modelo de regresión concebido con un proceso SPSS que exponga la interrelación que "la-libre-intención-de-permanencia" en ese centro (vecindario de Sainte-Marie) guarda con un conjunto de las variables más representativas de mejoría residencial en vivienda/servicios desde la perspectiva de las necesidades/impedancias (dificultades para lograrlo). La idea aquí es la de estimar el nivel de atracción central dentro de la limitaciones de un proyecto-piloto. Las variables independientes "ingreso-mensual", "régimen-depropiedad", "impedancia-de-mejoría-residencial", "necesidad-de-mejoría-en-servicios-de-salud", "impedancia-demejoría-en-servicios-de-salud", y de "impedancia-de-mejoría-en-transporte" fueron las más explicativas del comportamiento de la variable dependiente "libre intención de permanencia". La investigación confirma que la mejoría dada no es significativa en Sainte-Marie así como la atracción y permanencia locales en donde el valor del estudio radica en la re-evaluación de la visión parcial que el censo oficial ofrece.

Palabras Clave: Montreal, Espacio Central, Sainte Marie, “Libre Intención Permanencia”, Regresión Lineal.

DOI: 10.23881/idupbo.020.2-10e 